\title{
Depot medroxyprogesterone and bone mineral density
}

P J Ryan, MD, FRCP, Consultant Physician, Department of Nuclear Medicine, Medway Hospital, Windmill Road, Gillingham, Kent, UK; S P Singh, MBBS, Dip Obs, General Practitioner, Chatham, Kent, UK; J Guillebaud, FRCOG, MFFP, Medical Director, Margaret Pyke Centre, 73 Charlotte Street, London W1P 1LB, UK

Correspondence: Dr P J Ryan, Consultant Physician, Department of Nuclear Medicine, Medway Hospital, Windmill Road, Gillingham, Kent ME7 5NY, UK

(Accepted $11^{\text {th }}$ November 2001)

The Journal of Family Planning and Reproductive Health Care 2002: 28(1): 12-15

\section{Abstract}

Objective. To investigate depot medroxyprogesterone (DMPA)-associated bone loss in a general practice setting. Design. Forty-eight patients from a single practice who had used DMPA for contraception for more than 2 years. All patients had a serum oestradiol and if the serum level was $<52$ pmol/l or $>52$ pmol/ with menopausal symptoms, bone mineral densitometry (BMD) measurements were made at the lumbar spine $(L S)$ and femoral neck $(F N)$ using dualenergy $x$-ray absorptiometry (DEXA). Thirty-two patients had bone densitometry, of whom 27 had a serum oestradiol $<52$ pmolll and five $>52$ pmol/l associated with menopausal symptoms. Of the remaining 16 patients, nine patients had a serum oestradiol $<52$ pmol/ but did not have a BMD as they moved away (five women) or switched to another contraceptive (four women).

Results. BMD results showed a significantly reduced bone mass at both sites with mean Z score LS -0.84 (95\% CI -1.17 to -0.52$)$ and $F N-0.32$ (95\% CI -0.62 to -0.02). Eighteen women (56\% of 32 women) had either osteopenia (15 cases) ( T score <-1.0) or osteoporosis (three cases) ( $T$ score $<-2.5)$ at the $L S$. There were trends to an association of a family history of height loss or tobacco smoking (current or past) for $L S$ and FN Z scores that did not quite achieve significance. There was also a trend to lower body weight in those with a possible family history of osteoporosis or who were smokers and an inverse correlation of weight with BMD at the FN $(p<0.05)$ and $a$ non-significant inverse correlation at the $L S$.

Conclusion. The present results demonstrate that a low bone mass should be considered in patients with prolonged DMPA usage especially if they have risk factors for osteoporosis.

\section{Introduction}

Injection of depot medroxyprogesterone acetate (DMPA) is a highly effective reversible contraceptive independent of user's memory apart from remembering the 12-weekly injection. There have, however, been concerns for some years regarding the effect of DMPA on bone mass. This is intuitively reasonable given the subnormal levels of serum oestradiol typical of the early follicular phase often produced by this treatment. Low bone mineral density (BMD) associated with a low serum oestradiol observed in other premenopausal groups such as those with anorexia nervosa or amenorrhoeic athletes supports this concern. ${ }^{1-3}$ Women aged under 40 years with amenorrhoea due to other causes such as primary ovarian failure, hypopituitarism, hyperprolactinaemia, and use of luteinising hormonereleasing hormone (LHRH) analogues have also been shown to have a reduced bone mass. ${ }^{4-6}$

A study published in 1991 suggested a low bone mass was associated with DMPA users ${ }^{7}$ but was subjected to some criticism because of being a cross-sectional design, containing a large number of smokers, and lacking oestradiol measurements and pretherapy BMD. ${ }^{8}$ Some of the bone loss identified in this study appeared to be reversible from subsequent data published by the same group. ${ }^{9}$ Other work has suggested anxiety about bone loss with DMPA may be unnecessary. ${ }^{10,11}$ Whether these varying results relate to different subgroups of patients on DMPA is unclear. It is possible that only those with the lowest levels of serum oestradiol on treatment are at risk. Concern raised by previous published work was reinforced from clinical experience of one of the authors (S P Singh) who found that many of her patients having Depo-Provera ${ }^{\circledR}$ had symptoms similar to the peri- and postmenopause.

We report a study of a cohort of patients on DMPA from a single general practice who were found to have very low serum oestradiol levels, as this group should represent those at greatest risk of bone loss.

\section{Methods}

Injections of Depo-Provera ${ }^{\circledR}$ (DMPA) were offered together with other methods as a first-line method of contraception to women aged 15-49 years in a single general practice from January 1994 to January 1999. A comprehensive personal, family and social history was noted and thorough counselling explaining possible side effects including hypooestrogenism was given. In all, 147 women were treated with Depo-Provera ${ }^{\circledR}$. Patients were injected at $11-12$ week intervals, or more frequently if there was breakthrough bleeding (but not earlier than 6 weeks from the last injection). A record was kept of duration of treatment, number of injections, blood pressure, weight, side effects and patient satisfaction. Serum oestradiol was measured shortly before an injection after at least 2 years use. Information was acquired by questionnaire at the time of bone densitometry on risk factors for osteoporosis including use of oral steroids, personal history of fracture, use of steroids, smoking and family history in a first-degree relative.

In spite of DMPA being a convenient method of contraception, there was a discontinuation rate of $69 \%$ over 3 years' usage with the majority of patients stopping after 9-18 months due to side effects. Of the 147 women, 48 were still having DMPA after 2 years and had their serum oestradiol measured. Patients with a serum oestradiol $<52$ pmol/l (lower limit Medway laboratory range) (27 cases) or menopausal symptoms despite a higher oestradiol (five cases) were investigated with bone densitometry. Sixteen patients were not scanned, of whom nine had a serum oestradiol $<52 \mathrm{pmol} / \mathrm{l}$, of whom five had moved from the area, and four decided to discontinue treatment. A 
further seven patients had a serum oestradiol $>100 \mathrm{pmol} / \mathrm{l}$. BMD measurements were made at the lumbar spine (L1-L4) (LS) and femoral neck (FN) using a Hologic (Madison, WI, USA) QDR 4500C dual-energy x-ray absorptiometry (DEXA) device. BMD was measured within 3 months of referral and results were compared to the Hologic normal reference range at the LS and National Health and Nutrition Examination Survey (NHANES) three reference range at the $\mathrm{FN} .{ }^{12}$ These reference ranges have been acquired on large groups of normal randomly selected largely Caucasian women and are widely accepted and utilised. Height (Harpenden Stadeometer) and weight were measured when patients attended for their scan.

Data were described using the mean, standard deviation (SD) and 95\% confidence intervals (CI). Associations of BMD and weight with family history of osteoporosis or tobacco smoking (current or past) were examined using Student's $t$-test. Pearson's correlation coefficient was calculated to examine the relationship between weight and BMD. All statistical calculations were performed using Microsoft Excel 1997.

\section{Results}

The 48 women who were DMPA users were all white Caucasians. Of the 16 patients not scanned, nine had a serum oestradiol $<52 \mathrm{pmol} / \mathrm{l}$ and seven $>100 \mathrm{pmol} / \mathrm{l}$. The 32 whose serum oestradiol was $<52 \mathrm{pmol} / \mathrm{l}$ or who had menopausal symptoms were aged 19-53 years (mean 34) with 11 patients aged 19-29 years, ten aged 30-39 years and 11 aged $>40$ years. The average weight of these women was $66.6 \mathrm{~kg}$ (SD 13.9, range 49-102) which was normal for the mean height of 163 (SD 6.6) $\mathrm{cm}^{13}$ and signified a body mass index (BMI) of 25.1. The mean length of DMPA usage in these 32 women was 52 months (SD 22). The results of the bone density measurements are given in Table 1 with $\mathrm{T}$ and $\mathrm{Z}$ scores to enable comparison with young adult and age-matched normal reference ranges, respectively. Both $T$ and $\mathrm{Z}$ scores are below the mean with results at the LS an average of 1 SD below the normal young adult Caucasian reference mean. This corresponds to a reduction in bone mass of about $10 \%$. At the FN a similar trend was observed, with measurements significantly reduced. The $95 \%$ CI were for the LS T score -1.41 to -0.75 , FN T score -0.87 to -0.23 , LS Z score -1.17 to -0.52 and FN Z score -0.62 to -0.02 . Table 2 shows results of BMD, $T$ and $Z$ scores divided into age bands. Table 3 shows results for numbers of patients below certain cut-off $\mathrm{T}$ and $\mathrm{Z}$ scores.

Table 1 Summary of BMD, $T$ and $Z$ score results

\begin{tabular}{lllll}
\hline Site & Mean & SD & SE & $95 \%$ CI \\
\hline LS BMD $\left(\mathrm{g} / \mathrm{cm}^{2}\right)$ & 0.927 & 0.099 & 0.018 & \\
LS T score & -1.08 & 0.894 & 0.158 & -1.41 to -0.75 \\
LS Z score & -0.84 & 0.882 & 0.156 & -1.17 to -0.52 \\
FN BMD $\left(\mathrm{g} / \mathrm{cm}^{2}\right)$ & 0.787 & 0.092 & 0.016 & \\
FN T score & -0.55 & 0.880 & 0.155 & -0.87 to -0.23 \\
FN Z score & -0.32 & 0.810 & 0.143 & -0.63 to -0.02 \\
\hline
\end{tabular}

BMD, Bone mass density; CI, confidence intervals; FN, femoral neck; LS, lumbar spine; SD, standard deviation; SE, standard error.

There were three patients who were osteoporotic and one who was almost osteoporotic $(\mathrm{T}=-2.4)$ at the LS and based on the Hologic reference range no more than one patient would be expected by chance in 32 normal women of this age. The principal risk factors in this group of patients that may be expected to affect BMD were examined. Overall, of
Table 2 BMD, $T$ and $Z$ scores divided according to age bands ${ }^{a}$

\begin{tabular}{lllll}
\hline Site & $\begin{array}{l}\text { Age 19-29 years } \\
(\mathrm{n}=11)\end{array}$ & $\begin{array}{l}\text { Age 30-39 years } \\
(\mathrm{n}=10)\end{array}$ & $\begin{array}{l}\text { Age 40+ years } \\
(\mathrm{n}=11)\end{array}$ \\
\hline BMD LS $\left(\mathrm{g} / \mathrm{cm}^{2}\right)$ & $0.944(0.083)$ & $0.975(0.095)$ & $0.868(0.096)$ \\
LS T score & $-0.93(0.75)$ & $-0.66(0.86)$ & $-1.61 \quad(0.86)$ \\
LS Z score & $-0.81(0.79)$ & $-0.59(0.86)$ & $-1.10(0.98)$ \\
BMD FN $\left(\mathrm{g} / \mathrm{cm}^{2}\right)$ & $0.815(0.12)$ & $0.812(0.065)$ & $0.736(0.067)$ \\
FN T score & $-0.31(1.05)$ & $-0.32(0.81)$ & $-0.99(0.61)$ \\
FN Z score & $-0.41(0.94)$ & $-0.07(0.86)$ & $-0.46(0.62)$ \\
\hline
\end{tabular}

${ }^{a}$ Values given are means and standard deviations (in parentheses).

For abbreviations see Table 1

Table 3 Percentages of the 32 patients below certain $T$ and $Z$ cut-off scores

\begin{tabular}{lrll}
\hline Site & LS & FN & LS and FN \\
\hline Osteoporotic $(\mathrm{T}<-2.5)$ & $3(9 \%)$ & 0 & 0 \\
Osteopenic $(\mathrm{T}<-1.0,>-2.5)$ & $14(44 \%)$ & $9(28 \%)$ & $8(25 \%)$ \\
Lowest $2.5 \%$ population $(\mathrm{Z}<-2.0)$ & $4(13 \%)$ & 0 & 0 \\
Lowest 17\% population $(\mathrm{Z}<-1.0)$ & $15(47 \%)$ & $8(25 \%)$ & $7(22 \%)$ \\
\hline
\end{tabular}

For abbreviations see Table 1.

the 32 patients 13 were smokers, including ex-smokers or current smokers. Twelve patients had a family history of osteoporosis, which was considered positive in virtually all cases by the non-specific report of a loss of height with ageing in a first-degree relative. Of the three osteoporotic patients, two had a family history and these two were both smokers. Of the 15 spine osteopenic patients, six had a family history and six were smokers. Respective values for patients osteopenic at the hip were family history, four, and smoker, six. In the cohort one patient had a wrist fracture, and two were on add-back oestrogen at the time of scanning for less than 1 year. One patient who was osteopenic at LS and $\mathrm{FN}$ was on a modest dose of steroids, $2 \mathrm{mg} /$ day of prednisolone, and was also a smoker.

Mean LS and FN T scores, Z scores and weight comparing those who were smokers or who had a family history $(\mathrm{n}=20)$ versus those without such risk factors are shown in Table 4 There was a trend to an association of $\mathrm{Z}$ scores with the presence of the above risk factors that almost achieved significance. Correlation coefficients for weight versus $\mathrm{BMD}, \mathrm{Z}$ score and T score were at the LS $\mathrm{r}=0.31(\mathrm{p}>0.05)$, $r=0.27(p>0.05)$ and $r=0.31(p>0.05)$. Respective results at the FN were $r=0.42(\mathrm{p}<0.05), r=0.47(\mathrm{p}<0.05)$ and $\mathrm{r}=0.45(\mathrm{p}<0.05)$. There was a non-significant trend to an association of weight with family history or smoking with mean weight for those with risk factors $63.6 \mathrm{~kg}$ (SD 15.0) and without risk factors 69.0 (SD 11.7) and 95\% CI for difference -5.1 to 15.9 . The weights of the different $\mathrm{T}$ and $\mathrm{Z}$ score groups are shown in Table 5. Correlation coefficients from regression analysis for years of DMPA usage versus $\mathrm{T}$ score were $r=0.005$ for $\mathrm{LS}$ and $r=0.02$ for $\mathrm{FN}$.

Table 4 Spine and femoral neck $T$ and $Z$ scores, and weight in patients with and without a family history of osteoporosis or smoking

\begin{tabular}{|c|c|c|c|}
\hline Measurement & $\begin{array}{l}\text { Family history } \\
\text { or smoking } \\
(\mathrm{n}=20)\end{array}$ & $\begin{array}{l}\text { No family history } \\
\text { or smoking } \\
(\mathrm{n}=12)\end{array}$ & $\begin{array}{l}\text { Difference } \\
\text { in mean } \\
(95 \% \mathrm{CI})\end{array}$ \\
\hline LS T s & $-1.31(\mathrm{SD} 0.84)$ & $-0.70(\mathrm{SD} 0$ & $0.61(-0.04 t$ \\
\hline LS Z score & -1.08 (SD 0.89) & $-0.45(\mathrm{SD} 0.76)$ & $0.63(0.00$ to 1.26$)$ \\
\hline FN T score & $-0.82(\mathrm{SD} 0.91)$ & $-0.10(\mathrm{SD} 0.63)$ & $0.72(0.11$ to 1.33$)$ \\
\hline FN Z score & $-0.58(\mathrm{SD} 0.88)$ & $0.12(\mathrm{SD} 0.41)$ & $0.46(-0.05$ to 1.45$)$ \\
\hline Weight (kg) & $63.6(\mathrm{SD} 15.0)$ & $69.0(\mathrm{SD} 11.7)$ & $5.4(-5.1$ to 15.9$)$ \\
\hline
\end{tabular}

For abbreviations see Table 1 . 
Table 5 Weight (in kilograms) of patients depending on $T$ and $Z$ score groups $^{a}$

\begin{tabular}{lll}
\hline Site & LS & FN \\
\hline $\mathrm{T}<-2.5$ & $55.0(6.0) \quad(\mathrm{n}=3)$ & \\
$\mathrm{T}<-1.0,>-2.5$ & $66.1(8.7) \quad(\mathrm{n}=14)$ & $58 .(6.2) \quad(\mathrm{n}=9)$ \\
$\mathrm{T}>-1.0$ & $73.4(18.7)(\mathrm{n}=15)$ & $68.9(14.6)(\mathrm{n}=23)$ \\
$\mathrm{Z}<-2.0$ & $55 \quad(4.9)(\mathrm{n}=4)$ & \\
$\mathrm{Z}<-1.0,>-2.0$ & $62.4(9.4)(\mathrm{n}=15)$ & $56.3(6.8) \quad(\mathrm{n}=8)$ \\
$\mathrm{Z}>-1.0$ & $70.6(16.0)(\mathrm{n}=13)$ & $68.8(14.6)(\mathrm{n}=24)$ \\
\hline
\end{tabular}

avalues given are means and standard deviations (in parentheses).

For abbreviations see Table 1.

\section{Discussion}

The present results are suggestive that long-term suppression of serum oestradiol due to use of injectable DMPA may be causally associated with low BMD, at least in a subgroup who were selected by virtue of particularly low oestradiol levels $(<52 \mathrm{pmol} / \mathrm{l})$ or the development of menopausal symptoms.

However, the present study, in common with most other work on this subject, is cross-sectional in design and pretreatment scans were not performed. It therefore remains possible that the reduced bone mass we observed was at least in part caused by pre-existing genetic or lifestyle factors intrinsic to the users of DMPA and not DMPA itself. As expected, those with a possible family history of osteoporosis or a history of tobacco smoking showed a trend to a lower bone mass. Family history was largely reported as height loss in a first-degree relative and in some individuals this may not necessarily represent true osteoporosis. The results are nevertheless compatible with the view that those with a family history of osteoporosis or who are smokers and who are users of DMPA are at particular risk of bone loss. It should be noted that those who continued DMPA may have had more risk factors for osteoporosis than those who did not and this could have increased the proportion of those with risk factors in the present study. For example, non-smokers who wished to discontinue DMPA because of side effects could have been more easily transferred to the oral contraceptive pill. The trend towards a lower weight in those with lower BMD which achieved significance at the FN suggests body mass is also an important risk factor for low bone mass. The trend to an association of the risk factors of family history and smoking with weight suggests they may be markers, in part, for low body mass.

The lack of a control group is another potential criticism. However, internationally recognised reference ranges were used that are widely accepted in the UK. With respect to the LS reference range there are several studies showing that the UK Caucasian population has a similar distribution of measurements to the Hologic normal reference range. ${ }^{14}$

Some improvement in bone mass may occur following the cessation of therapy which would tend to reduce concern regarding impact of DMPA on bone mass. This is supported by the study of Cundy et al. in which there was a $3.4 \%$ rise in bone mass at the spine in the first year ${ }^{9}$ after discontinuation. Obviously whether such improvements continue in subsequent years is unknown. Another study has shown no difference in the bone mass of postmenopausal women between previous users and never users. ${ }^{15}$ However, whether bone mass improves after therapy cannot at present be assumed; and even if this does occur, on the evidence provided here some DMPA users, albeit a minority, are already osteoporotic and susceptible to low trauma fracture.
There are a number of studies supportive of the present work including a case control study from Brazil ${ }^{16}$ examining spine and hip bone mass where the mean serum oestradiol among users was $56 \mathrm{pg} / \mathrm{l}$. Further work from the New Zealand group reported significant osteopenia in a much larger series ${ }^{17}$ and demonstrated bone loss following oral medroxyprogesterone. ${ }^{18}$ Recent work in abstract form from this group has shown continued bone loss in long-term injectable DMPA users when followed by sequential axial BMD over 2 years. ${ }^{19}$ Data on spine measurements have also been supported by a case control study of forearm measurements 50 DMPA users who had not used oral contraceptives for more than 5 months and were matched for age, weight and race $^{20}$ and a further recent large international study of DMPA users. ${ }^{21}$ A cross-sectional study of younger women has shown more pronounced bone loss in 18-21-year-olds compared to older women, ${ }^{22}$ and a study among adolescents has shown bone loss amongst users compared to an increase in bone mass among nonusers. ${ }^{23}$ A recent cross-sectional study of 174 adolescents has shown declining BMD related to length of usage. ${ }^{24}$

Some studies have failed to demonstrate an association of DMPA use with bone loss, such as the large study of 153 women by Gbolade et al. ${ }^{10}$ This may be due to the inclusion of many patients whose oestradiol was not suppressed to usual postmenopausal levels and there were only 16 women with a serum oestradiol $<50 \mathrm{pmol} / \mathrm{l}$. Other work that has failed to show an association of DMPA use and bone loss has only examined the forearm, which is likely to be a less sensitive site than the spine due to a greater proportion of cortical bone..$^{11,25}$

In conclusion, judging from the evidence of the present study based on all the users in a single general practice, $75 \%$ of DMPA users for 2 or more years will have very low oestradiol levels $(<52 \mathrm{pmol} / \mathrm{l})$ prior to their next injection, and of the latter (including those with menopausal symptoms and oestradiol $<100 \mathrm{pmol} / \mathrm{l}$ ) about $50 \%$ will have spinal osteopenia or osteoporosis. It may be that DMPA use acts as a marker for having a low bone density, even if the aetiology is complex and not all due to the contraceptive. The practical implications of these findings remain unclear, however, given the following:

(1) The work was undertaken in a relatively poor urban setting and the findings may not be applicable outside of a similar general practice context.

(2) The uncertainty about causation, what proportion is a DMPA effect and what is due to the type of women who are long-term users of DMPA.

(3) The uncertainty about the reversibility of lost BMD after DMPA cessation.

(4) The concerns and financial implications generated by any testing policy.

(5) The lack of an official practical management protocol from the Faculty of Family Planning and Reproductive Health Care, or the World Health Organization (WHO), aside from a statement by the latter that in women under 18 years and over 45 years DMPA is relatively contraindicated (WHO-2) and 'there are theoretical concerns about hypo-estrogen effect' ${ }^{26}$

(6) Above all, the great value of this contraceptive to many women (and the well-known risks of pregnancy if they cease to use it).

Pending more data it is the view of these authors that the long-term use of DMPA should in general be avoided by women with indisputable additional risk factors for osteoporosis without prescreening by bone densitometry. In the remainder after (arbitrarily) 5 years use and earlier if 
there are relevant symptoms, the issue of possible hypooestrogenism should be discussed. Pre-injection oestradiol measurements may be offered if the woman does not wish to change her contraceptive, and results $<52 \mathrm{pmol} / 1 \mathrm{might}$ reasonably indicate bone densitometry, if available, prior to further long-term use.

\section{Statements on funding and competing interests}

Funding. None declared.

Competing interests. None declared.

References

Wolman RL, Clark P, McMally E, Harries M, Reeve J. Menstrual state and exercise a determinants of spinal trabecular bone density in female athletes. BMJ 1990; 301: 516-518. Osteoporosis Int 1997; 3: 311-315.

3 Seeman E, Szmukler GI, Formica C, Tslamandris C, Mestrovic R. Osteoporosis in anorexi nervosa: the influence of peak bone density, bone loss, oral contraceptive use and exercise. $J$

Bone Miner Res 1992; 7: 1467-1474.
Scharla SH, Minne HW, Waibel-Treber S, et al. Bone mass reduction after estrogen deprivation by long acting gonadotrophin-releasing hormone agonists and its relation to pretreatmen concentrations of 1,25 dihydroxyvitamin D3.J Clin Endocrinol Metab 1990; 70; 790-793.

Davies MC, Hall ML, Jacobs HS. Bone mineral loss in young women with amenorrhoea. BMJ

6 Biller BMK, Baum HB, Rosenthall DI, et al. Progressive trabecular osteopenia in women with

hyperprolactinemic amenorrhoe. J Clin Endocrinol 1992; 75; 692-697.

Cundy $\mathrm{T}$, Evans $\mathrm{M}$, Roberts $\mathrm{H}$, et al. Bone density in women receiving depot medroxyprogesterone acetate for contraception. BMJ 1991; 303: 13-16.

Correspondence. DMPA and bone density. BMJ 1991; 303: 467-468.

Cundy T, Cornish J, Evans MC, Roberts H, Reid IR. Recovery of bone density in women receiving depot medroxyprogesterone acetate for contraception. BMJ 1993; 308: 247-248.

Gbolade B, Ellis S, Murby B, Randall S, Kirkman R. Bone density in long term users of depo medroxyprogesterone acetate. Br J Obstet Gynaecol 1998; 105: 790-794.
11 Taneepanichskul S, Intaraprasert S, Theppisai U, Chaturachinda K. Bone mineral density in long term depot medroxyprogesterone acetate acceptors. Contraception 1997; 56: 1-3. Looker AC, Wahner HW, Dunn WL, et al. Updated data on proximal femur bone mineral levels of US adults. Osteoporosis Int 1998; 8: 468-489.

13 Statistical Bulletin Metropolitan Life Foundation. 1983; 64: 2-9.

14 Ryan PJ, Blake GM, Fogelman I. Post menopausal screening for osteopaenia. Br J Rheumato

5 Orr-Walker BJ, Evans MC, Ames RW, et al. The effect of past use of the injectable contraceptive depot medroxyprogesterone acetate on bone mineral density in normal post-

16 Costa Paiva L, Pinto-Neto AM, Faundes A. Bone density among long term users of medroxypro

. Colmes H, Reid IR. Spinal bone density in women using depot medroxyprogesterone contraception. Osteoporosis Int 1996; 6 (Suppl. 1): 274.

18 Cundy T, Farquhar CM, Cornish J, Reid IR Short term effects of high dose ora medroxyprogesterone in pre menopausal women. J Clin Endocrinol Metab 1996; 81: 1010-1017.

19 Cundy T, Ames R, Clearwater J, et al. Bone density in long-term DMPA users: a double blin randomised controlled trial of estrogen replacement therapy. J Bone Miner Res 2001; 16 (Suppl.): S221

0 Bahamondes L, Perrotti M, Castro S, Faundes D, Petta C, Bedsone A. Forearm bone density in users of Depo Provera as a contraceptive method. Fertil Steril 1999; 71: 849-852.

1 Petitti DB, Piaggio G, Mehta S, Cravioto MC, Meirik O, for the WHO study of hormon contraception and bone health. Steroid hormone contraception and bone mineral density:

22 Scholes D, Lacroix AZ, Ott SM, Ichikawa LE, Barlow W. Bone mineral density in wome using depot medroxyprogesterone acetate for contraception. Obstet Gynaecol 1999; 93: using depot

23 Cromer BA, MacArdle Blair J, Mahan JD, Zibners JD, Naumovski Z. A prospective comparison of bone density in adolescent girls receiving depot medroxyprogesterone acetate
(Depo-Provera), levonorgestrel (Norplant) or oral contraceptives. J Pediatr 1996; 129 671-676.

24 Scholes D, LaCroix A, Ichikawa L, Barlow W, Ott S. Depot medroxy progesterone acetate an bone mineral density in adolescent women. J Bone Miner Res 2001; 16 (Suppl. 1): S235.

Naessen T, Olsson SE, Gudmundson J. Differential effects on bone density of progestoge only methods for contraception in premenopausal women. Contraception 1995; 52: 35-39.

World Healh Organization (WHO). Improving access to quality care in family planning: medical eligibility criteria for contraceptive use. WHO/RHR/00.02. Geneva: World Healt 